\title{
DESCRIÇÃO DE DUAS ESPÉCIES NOVAS DE Cerathybos BEZZI (DIPTERA, EMPIDIDAE, HYBOTINAE).
}

\author{
Rosaly ALE-ROCHA
}

RESUMO - Duas espécies novas de Cerathybos Bezzi (Diptera, Empididae, Hybotinae) são descritas: Cerathybos bezzii, do Equador, Colômbia e Bolivia, e Cerathybos nigripes, do Peru, incluindo os primeiros machos conhecidos deste gênero; um novo registro de $C$. schnusei é feito para a Colômbia e aspectos da terminália masculina são discutidos.

Palavras-chave: Diptera, Empididae, Cerathybos, Taxonomia, Distribuiçào.

Description of Two New Species of Cerathybos Bezzi (Diptera, Empididae, Hybotinae).

ABSTRACT - Two new species of genus Cerathybos Bezzi (Diptera, Empididae, Hybotinae) are described and illustrated: Cerathybos bezzii, from Equador, Colombia and Bolivia, and Cerathybos nigripes, from Peru, including the first known males of this genus; new records of $C$. schnusei are made and aspects of male terminalia are discussed.

Key-words: Diptera, Empididae, Cerathybos, Taxonomy, Distribution.

\section{Introdução}

O gênero neotropical Cerathybos Bezzi (Diptera, Empididae, Hybotinae) é pequeno, inclui duas espécies conhecidas, C. schnusei Bezzi, 1909, do Peru, e C. catharinensis Ale-Rocha \& Rafael, 1995, do Brasil; foi recaracterizado e a espécie-tipo redescrita em Rafael \& Ale-Rocha (1995) e uma chave para espécies foi apresentada em Ale-Rocha \& Rafael (1995). Exemplares deste gênero são raros em coleções e isso provavelmente se deve à falta de maior esforço de coleta. Até o presente, somente fềmeas eram conhecidas.

Os adultos caracterizam-se pela cabeça mais alta que larga, ocipício dilatado; antena localizada acima do meio da cabeça; flagelo grande, largo, abaulado dorsalmente; probóscide robusta, labelo membranoso, com pseudotraquéias; palpos curtos e delgados com uma cerda pré-apical curta; face longa e estreita; facetas superiores e inferiores pequenas; escuto quase plano dorsalmente, não corcunda; escuto e abdome brilhantes, sem pruína dorsal; Rs curta; fêmur posterior dilatado, com cerdas espiniformes ventrais.

Cerathybos Bezzi e Euhybus Coquillett são considerados gruposirmãos e formam o grupo mais derivado de Hybotinae (Ale-Rocha, 1998). São os únicos gêneros neotropicais desta subfamília com labelo membranoso e pseudotraquéias presentes. A terminália masculina de Cerathybos assemelha-se em muitos aspectos à de Euhybus: epândrio dividido dorsalmente em duas lamelas; hipândrio com o lobo esquerdo reduzido; braços hipandriais alargados distalmente e unidos dorsalmente, formando uma câmara ao redor do

Instituto Nacional de Pesquisas da Amazônia (INPA), Coordenação de Pesquisas em Entomologia, Caixa Postal 478,69011-970, Manaus - Amazonas, Brasil, alerocha@inpa.gov.br 
falo; gonóstilos assimétricos; apódema ventral dos gonóstilos não esclerotinizado, indistinto; falo robusto, com dois apódemas ejaculadores desenvolvidos; somente o surstilo direito articulado. $\mathrm{O}$ gênero distingue-se de Euhybus pelas cerdas dorsais ausentes nos tarsos anteriores e médios e formato do flagelo.

Neste trabalho são descritas duas espécies novas: Cerathybos bezzii e Cerathybos nigripes e feito um registro novo de Cerathybos schnusei para a Colômbia.

$\mathrm{O}$ material estudado pertence à Coleção de Invertebrados do Instituto Nacional de Pesquisas da Amazônia (INPA) e ao The Natural History Museum (BMNH).

A terminologia adotada segue McAlpine (1981) exceto para a terminália, onde foram seguidos Cumming et al. (1995). Abreviaturas usadas para a posição das cerdas: $A$, anterior; $A D$, ântero-dorsal; $\mathrm{AV}$, ântero-ventral; $\mathrm{PD}$, póstero-dorsal; $\mathrm{PV}$, póstero-ventral; $\mathrm{V}$, ventral.

\section{Chave para as espécies de} Cerathybos (modificada de AleRocha \& Rafael, 1995):

1. Pernas anterior, média e posterior concolores; fêmures e tíbias homogeneamente coloridos .2

1 '. Pernas anterior e média com coloração diferente da posterior; fêmur e/ou tíbia posterior bicoloridos 3

2. Ápice do flagelo prolongado (Fig. 1, Ale-Rocha \& Rafael, 1995); pernas castanho-claras, exceto os dois tarsômeros basais amarelos e os demais castanhos; 1ำ tarsômero médio com 2 cerdas espiniformes sub-basais posteriores; 5-6 pares de cerdas escutelares delgadas, amarelas, par préapical robusto e escuro C. catharinensis Ale-Rocha \& Rafael

2'. Ápice do flagelo não prolongado (Fig. 9); pernas castanho-escuras a pretas exceto os dois tarsômeros basais anteriores e médios castanhos; tarsômero médio sem cerdas destacadas; 13 pares de cerdas escutelares pretas e robustas

\section{C. nigripes sp.n.}

3. Fêmur posterior castanho-escuro, exceto a porção distal com $1 / 2$ dorsal e $1 /$ 3 anterior e posterior amarelos, tíbia posterior castanha; cerdas dorso-laterais do tergito 2 amarelas e delgadas; 9-10 pares de cerdas escutelares ........... $C$. schnusei Bezzi

3'. Fêmur posterior homogeneamente castanho a castanho-escuro, tíbia posterior amarela, com 1/3 basal castanho ou completamente castanha; cerdas dorsolaterais do tergito 2 castanhas; 8 pares de cerdas escutelares Cerathybos bezzii sp.n.

\section{Cerathybos bezzii sp.n. (Figs. 1-8, 10)}

Holótipo macho. Corpo $6,4 \mathrm{~mm}$. Asa 5,0 mm. Cabeça: antena castanha; flagelo cerca de 1,9 vezes mais longo que largo e 2,1 vezes mais longo que o escapo e pedicelo combinados; arista tão longa quanto a antena (Fig. 1); peças bucais castanho-claras; par ocelar curto e divergente. Pós-crânio preto, com pruinosidade cinza abaixo e castanha acima do meio; pós-oculares e ocipitais curtas, retas e esparsas; pós-oculares inferiores ausentes. Tórax: preto, exceto 
calo pós-alar amarelo e escutelo castanho, brilhante, com pruinosidade castanhoavermelhada na margem póstero-lateral do pronoto, notopleura, região préescutelar, escutelo e pleuras. Metade inferior do anepisterno e maior parte do catepistenro sem pruina, brilhantes. Pronoto curto com cerdas marginais eretas, mais longas e fortes que as do escuto. Cerdas do escuto castanhas, curtas e esparsas; acrosticais com 4-5 séries irregulares; série dorsocentral curta, interrompida na altura da primeira notopleural. Cerdas destacadas, mais robustas: 3 notopleurais; 1 pós-alar; 8 pares escutelares longos e robustos sendo o par apical divergente e os demais convergentes decrescendo discretamente de comprimento nos pares mais externos. Asa (Fig. 10) castanha. Halteres castanhos. Pernas: anterior e média castanhas exceto $1^{\circ}$ e $2^{\circ}$ tarsômeros amarelos; posterior castanho-escura, exceto ápice do fêmur, $1 / 3$ basal da tíbia e $2^{\circ}-5^{\circ}$ tarsômeros castanhos, $2 / 3$ distais da tíbia e $1^{\mathfrak{o}}$ tarsômero amarelos. Cerdas destacadas: tíbia anterior com $1 \mathrm{~A}$ pré-apical curta; tíbia média com $4 \mathrm{AD}$ curtas, $1 \mathrm{PD}$ e $1 \mathrm{~A}$ préapicais e $1 \mathrm{~V}$ apical; trocanter posterior com 1 espinho ventral; fêmur posterior com 3 cerdas AD (1 mediana, 1 no $1 / 4$ distal e 1 preapical), $3 \mathrm{~A}$ espiniformes ( 1 mediana, 1 submediana e 1 no $1 / 4$ distal), $7 \mathrm{AV}$ espiniformes, $1 \mathrm{PV}$ no $1 / 4$ distal, duas séries de espinhos robustos na face ventral sendo a série anterior com 7 espinhos e a posterior com 10. Tarsos simples, delgados, sem espinhos ou cerdas destacadas. Abdome: pretobrilhante, com pruína castanha no dorso do T1 e em todo o T8; cerdas castanhas, levemente mais longas nas laterais dos tergitos 1-3. Terminália (Figs: 2-8): lamela epandrial esquerda com ápice trífido, surstilo ausente; lamela epandrial direita mais curta que a esquerda com surstilo articulado; falo robusto com 2 apódemas ejaculadores subiguais em comprimento.

Fêmea: desconhecida.

Material tipo. Holótipo macho (BMNH): Ecuador. Napo, Muyuna, 5 $\mathrm{Km}$ w of Tena, $550 \mathrm{~m}$, 27.ix.1978, M. Cooper, BM 1995E-90. Parátipos: Colombia. Putumayo, Mocoa, 7-11.viii.1974 (M. Cooper), BM 1995E-90, 1 macho (INPA); Ecuador. Napo, Muyuna, $5 \mathrm{Km}$ w of Tena, $550 \mathrm{~m}, 27 . \mathrm{x} .1978$, M. Cooper, BM 1995E-90, 1 macho (BMNH); Bolivia. Beni, Rurrenabaque, 17.iv6.v.1979 (M. Cooper), BM 1995E-90, 1 macho (BMNH).

Condição do holótipo: terminália em tubo com glicerina, asa e antena direitas montadas entre lamínulas.

Variações: os exemplares da Colômbia e Bolívia têm a tíbia posterior completamente castanha; o número de cerdas destacadas no fềmur posterior varia: $3 \mathrm{AD}$ a $4 \mathrm{AD} ; 2 \mathrm{~A}$ a $3 \mathrm{~A}$; o tamanho varia de 5,9 a $6,4 \mathrm{~mm}$..

Registros geográficos: Equador, Colômbia e Bolívia.

Etimologia. O epíteto é um patronímico em homenagem a Mario Bezzi, pela grande contribuição para o conhecimento dos empidídeos do mundo.

\section{Cerathybos nigripes sp.n. (Figs. 9, 11)}

Holótipo macho. Corpo $6,8 \mathrm{~mm}$. Asa $5,7 \mathrm{~mm}$. Espécie semelhante a $C$. 


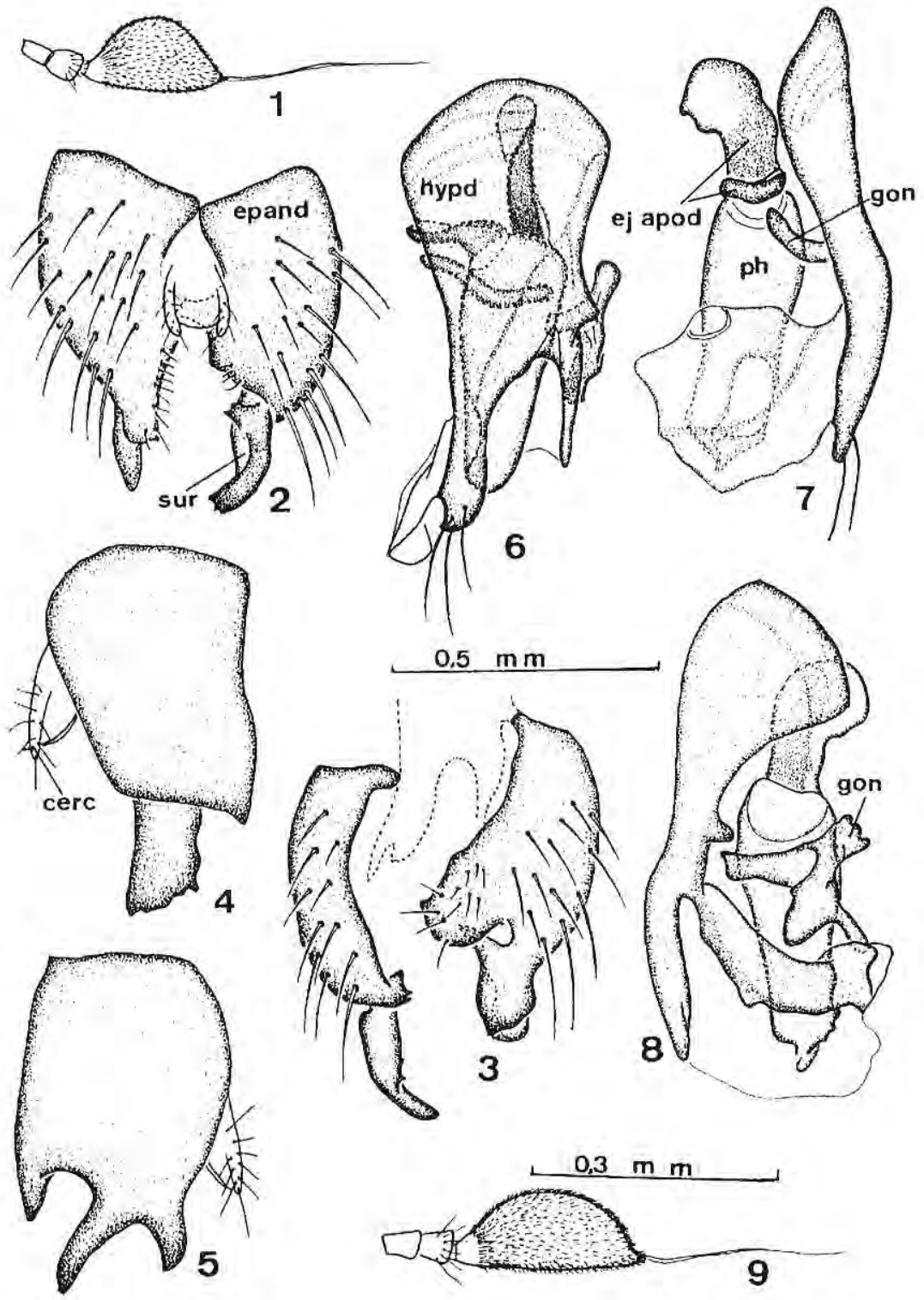

Figuras 1-9. Cerathybos bezzii sp.n., holótipo macho: 1, antena; 2, 3, terminália, vista dorsal e ventral (hipândrio não representado); 4,5, epândrio e cercos, vista lateral direita e esquerda; 6 8, hipândrio, falo e gonóstilos, vista ventral, lateral direita e esquerda. Fig. 9. Cerathybos nigripes sp.n., holótipo macho, antena. Figuras 1,$9 ; 2-8$ na mesma escala. 
bezzii, sp.n., exceto pelo que segue: flagelo 2,4 vezes mais longo que largo, 2,5 vezes mais longo que o escapo e pedicelo combinados; arista tão longa quanto o flagelo (Fig. 9); par ocelar paralelo; escutelo preto, concolor com o escuto; acrosticais com 4-6 séries irregulares; 13 pares de cerdas escutelares; asa castanho-escura com célula costal alargada (Fig. 11); pernas castanho-escuras a pretas exceto os dois tarsômeros basais anteriores e médios castanhos; tíbia anterior com 1 cerda P pré-apical mais robusta; fêmur posterior com 8 cerdas AV espiniformes e face ventral com 2 séries de 11 espinhos; abdome com cerdas pretas, e curtas, apenas discretamente mais longas nos tergitos 13. Terminália como em C. bezzii sp.n.

Fêmea: desconhecida.

Material tipo. Holótipo macho (BMNH): PERU. Huánuco, Tingo Maria, 1.v.1982, M. Cooper, BM 19995E-90.

Condições do holótipo: terminália em tubo com glicerina, asa e antena direitas montadas entre lamínulas.

Registro geográfico: Peru.

Etimologia. O epiteto é um adjetivo alusivo à coloração das pernas.

\section{Cerathybos schnusei Bezzi}

Cerathybos schnusei Bezzi, 1909:303, Fig. 1; Smith, 1967:14 (catálogo); Rafael \& Ale-Rocha, 1995:519, Figs. 1-4, 52 (redescrição); Ale-Rocha \& Rafael, 1995:189 (chave).

Espécie revisada por Rafael \& Ale-Rocha (1995). Neste trabalho amplia-se os dados sobre a distribuição geográfica do gênero.

Material examinado: PERU. Huánuco, Tingo Maria, 1.V.[19]82, M. Cooper, 1 fêmea (BMNH); COLÔMBIA. Putumayo, Mocoa, 12.ix.[19]78, M. Cooper, 1 fêmea (BMNH).

Registros geográficos: Peru, Brasil e Colômbia (novo registro).

\section{Agradecimentos}

A John Chainey (BMNH) pelo empréstimo do material.

\section{Bibliografia citada}

Ale-Rocha, R. 1998. Sistemática filogenética de Hybotinae (Diptera, Empididae). Tese de Doutorado, UFPR, 138 pp.
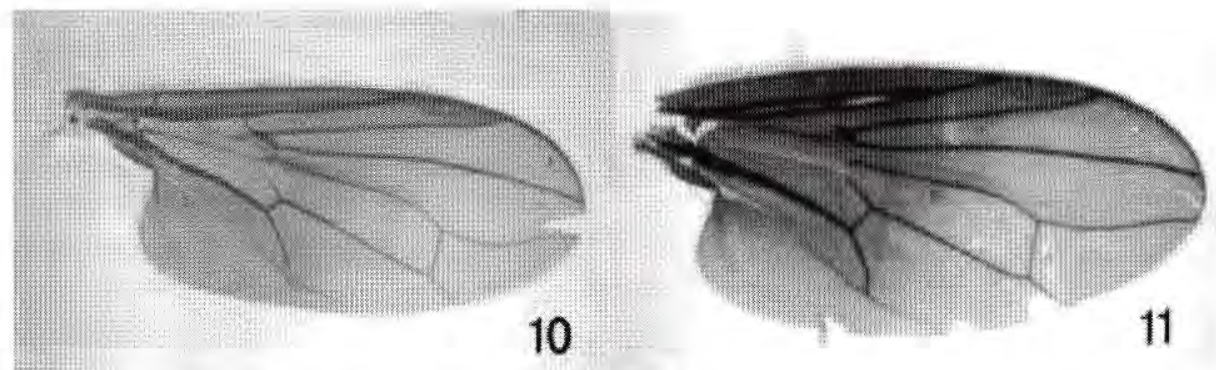

Figuras 10-11. Cerathybos bezzii sp.n., holótipo macho, asa direita; 11, Cerathybos nigripes sp.n., holótipo macho, asa direita. 
Ale-Rocha, R.; Rafael, J. A. 1995. Nova espécie e primeiro registro do gênero Cerathybos Bezzi no Brasil (Diptera, Empidoidea). Revta. bras. Ent. 39 (1):189-192.

Bezzi, M. 1909. Beitraege zur Kenntniss der südamerikanischen Dipterenfauna. Fam. Empididae. Nova Acta Acad. Caesar Leop. Carol. 91:297-406.

Cumming, J. M.; Sinclair, B. J.; Wood, D.M. 1995. Homology and phylogenetic implications of male genitalia in DipteraEremoneura. Ent. Scand. 26:121-152.

McAlpine, J. F. 1981. Morphology and terminology, pp:9-63, In: J.F.McAlpine et al (eds.) Manual of Neartic Diptera v.1, Ottawa, Res. Branch. Agriculture Canada, 674p.

Rafael, J. A.; Ale-Rocha, R. 1995. Revisão das espécies neotropicais de Empididae (Diptera) descritas por Mario Bezzi. I. Hybotinae. Revta, bras. Ent. 39 (3): 517-546.

Smith, K.G.V. 1967. Family Empididae (Empidae, Hybotidae), In: A catalogue of Diptera of Americas South of the United States. São Paulo, Departamento de Zoologia, Secretaria de Agricultura. v. 39, 67p.

Aceito para publicação em 13/05/2002 